\title{
The modelling of mononuclear phagocyte-connective tissue adhesion in vitro: application to disclose a specific inhibitory effect of Leishmania infection
}

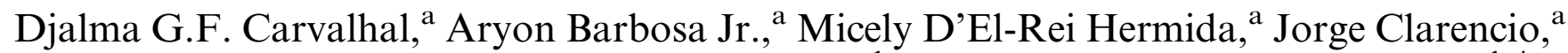 \\ Nathanael F. Pinheiro Jr., ${ }^{a}$ Patricia S.T. Veras, ${ }^{\mathrm{a}, \mathrm{b}}$ and Washington L.C. dos-Santos ${ }^{\mathrm{a}, \mathrm{b},{ }^{*}}$ \\ ${ }^{\text {a }}$ Centro de Pesquisas Gonçalo Moniz, Fundação Oswaldo Cruz, Rua Waldemar Falcão 121, 40295-001 Salvador, BA, Brazil \\ ${ }^{\mathrm{b}}$ Escola Bahiana de Medicina e Saúde Pública, Av. Dom João VI 274, Brotas 40290-000, Salvador, BA, Brazil
}

Received 12 March 2004; accepted 14 June 2004

Available online 20 July 2004

\begin{abstract}
In this work, we have developed an adhesion assay to study interactions between mononuclear phagocytes and connective tissue in vitro and show its potential use to study diseases caused by intracellular microorganisms. The assay reproduces most of the characteristics of macrophage adhesion to connective tissue in vivo, such as: preferential adhesion to inflamed connective tissue, divalent cation and integrin dependence, and up-regulation upon cell activation. The phagocyte adhesion to connective tissue was inhibited by infection with Leishmania $(58 \pm 22 \%, p<0.05)$ and was not affected by infection with Mycobacterium or by endocytosis of latex beads. Manganese partially reverted the loss in adherence produced by Leishmania infection, indicating that the mechanisms regulating the function of integrins are affected by cell infection with Leishmania. This assay might be a useful tool for the study of the mechanisms by which mononuclear phagocytes play a role in the immune-inflammatory response and in the development of lesions. (C) 2004 Elsevier Inc. All rights reserved.

Index Descriptors and Abbreviations: Adhesion assay; Cell adhesion; Macrophage adhesion; J774 cells; Leishmania amazonensis; Leishmania braziliensis; Leishmania chagasi; Mycobacterium fortuitum; Promastigotes; ANOVA, analysis of variance; CD, cluster designation for classification of cell markers; CS-1, connecting segment 1 of fibronectin; EDTA, ethylenediaminetetracetic acid; FACS, fluorescence activated cell sorting; FBS, fetal bovine serum; HBSS, Hanks' balanced salt solution; LFA-1, leukocyte activation antigen 1 ( $\beta 2$-integrin, CD11a/CD18); LPS, lypopolysaccharide; Mac-1, $\beta 2$-integrin named after macrophages (CD11b/CD18); PBS, phosphate-buffered saline; RGD, peptide containing RGD sequence; RPMI, Roswell Park Memorial Institute-1640 (tissue culture medium); SNK, Student-Newman-Keuls test; VCAM-1, vascular cell adhesion molecule 1
\end{abstract}

\section{Introduction}

Mononuclear phagocytes constitute a heterogeneous cell population, with a wide range of phenotypes and functional differentiation (Cavanagh and Von Andrian, 2002; Mantovani et al., 2002). These cells are involved in a variety of pathological processes and act as an important link between inflammatory and immune responses. In some chronic infectious diseases, such as leishmaniasis and tuberculosis, macrophages, and dendritic cells play a critical role in the genesis and

\footnotetext{
${ }^{*}$ Corresponding author. Fax: +55-71-356-2255.

E-mail addresses: wluis@cpunet.com.br,wluis@cpqgm.fiocruz.br (W.L.C. dos-Santos).
}

progression of lesions. During the inflammatory process, mononuclear phagocytes are stimulated to migrate from blood or from their primary homing sites to the inflammatory areas and from these inflammatory areas to lymph nodes (Moll et al., 1993; Randolph et al., 1999).

The cell capability to migrate or to remain in a specific site depends upon both its profile of expressed adhesion molecules and the functional status of these molecules (Springer, 1995). Hence, a variety of experimental models of cell adhesion and migration have been envisaged to study normal aspects of cell function and cell participation in disease (dos Santos et al., 1996; Loike et al., 1999; Pietschmann et al., 1992; Pryce et al., 1994). 
In 1976, Stamper and Woodruff described an adhesion assay using lymph node sections to study lymphocyte interaction with high endothelial venules (HEV) (Stamper and Woodruff, 1976). The Stamper and Woodruff's assay has, however, been criticized for using low temperature (Warren et al., 1993), favouring interactions mediated by non-energy requiring molecules (Marlin and Springer, 1987), and excluding most of the interactions mediated by activated integrins.

Integrins are responsible for the firm adhesion established between leukocytes and endothelium and also between leukocytes and connective matrix components (Carlos and Harlan, 1994). Stamper and Woodruff noticed, however, that raising the temperature during their adhesion assay would result in lower levels of cell adhesion to lymph node sections (Stamper and Woodruff, 1977). In spite of this observation, the Stamper and Woodruff assay has been performed using different ranges of temperature by other authors (Barbe et al., 1996; Chakravorty et al., 1999; Matsushita et al., 1998; Poston and Johnson-Tidey, 1996; Steffen et al., 1996; Symon et al., 1999), although in most of these studies the effect of varying the temperature has not been reported. Vora et al. (1995), using brain tissue, noticed that increase in temperature lead to a more widespread adherence of the cells to non-vascular areas. These authors interpreted this observation as an increase in non-specific adhesion. On the other hand, Grober and collaborators (Grober et al., 1993) draw attention to the possibility that such cell adherence to non-endothelial tissues represent receptor-mediated interactions of potential functional significance. According to this latter view, we adapted the model developed by Stamper and Woodruff, as described below, to the study of mononuclear phagocyte interactions with the connective tissue. In synthesis, the working hypotheses of the study described herein were that the so-called non-specific adhesions occurring at $37^{\circ} \mathrm{C}$ or room temperature (Coleman and Stanley, 1994; Vora et al., 1995) are actually mediated by energy-requiring adhesion pathways that commonly operate in vivo and that an adhesion assay taking into account this aspect would be useful for studying the mechanisms of diseases caused by intracellular microorganisms in which mononuclear phagocytes play a fundamental role in the defense and in the genesis of lesions.

In the initial set of experiments, we defined the optimal conditions under which the mononuclear phagocyte-connective tissue interactions occurred and performed experiments to confirm the nature and specificity of the interactions observed. In sequence, we studied the adherence of different mononuclear phagocytes to connective tissue and the changes induced by infection with two intracellular pathogens, Leishmania and Mycobacterium, using this system.

\section{Material and methods}

\subsection{Animals}

Eight- to 12-week-old BALB/c mice were obtained from the colony of the Gonçalo Moniz Research Center-FIOCRUZ (Salvador, Brazil). The animals were maintained under specific pathogen-free and controlled environmental conditions of humidity, temperature, light-dark cycle, and with commercial balanced mouse chow and water ad libitum. The experiments using animals were conducted in accordance with the Oswaldo Cruz Foundation guidelines for experimentation with animals (http://www.fiocruz.br/presidencia/vppdt/ index.htm).

\subsection{Sections of inflamed tissue}

Dorsal subcutaneous inflammatory air pouches were produced in BALB/c mice by the injection of $5 \mathrm{ml}$ of air and $200 \mu \mathrm{l}$ of soy oil containing $0.1 \%$ of croton oil. Three days after injection the animals were killed by cervical dislocation. Transversal slices of tissue from the inflammatory air pouch (skin and subjacent tissue) were collected, immersed in Histoprep (Fisher Scientific, USA), frozen in liquid nitrogen and preserved at $-70^{\circ} \mathrm{C}$ until use. For the adhesion assays, serial $7 \mu \mathrm{m}$ cryostat sections (perpendicular to the skin and the wall of the inflammatory air pouch) were collected onto glass slides previously coated with a gelatine (Sigma-Aldrich, USA) film $(0.5 \%$ gelatine solution in distilled water). Sections were air dried and fixed with 1\% glutaraldehyde (SigmaAldrich, USA) in phosphate-buffered saline (PBS) for $5 \mathrm{~min}$ or with cold $\left(-20^{\circ} \mathrm{C}\right)$ acetone for $3 \mathrm{~min}$. The sections were then washed with PBS and used in the experiments. The purpose of using glass slides pre-coated with gelatine was to minimize the monocyte/macrophage adherence to glass.

\subsection{Mononuclear phagocytes}

Most of the experiments were performed using the J774.G8 cell line (BCRJ No. CR028, generously provided by Dr. Radovan Borojevic, Federal University of Rio de Janeiro, Brazil). The cells were grown in RPMI1640 supplemented with $10 \%$ heat inactivated fetal bovine serum (FBS, Gibco-BRL, USA), $60 \mu \mathrm{g} / \mathrm{ml}$ gentamycin and $2 \mathrm{mM}$ glutamine (complete RPMI). Confluent cells were detached by washing with cold $\mathrm{Ca}^{2+}$ - and $\mathrm{Mg}^{2+}$-free Hanks' balanced salt solution (HBSS, Gibco-BRL, USA) and resuspended in complete RPMI. Mouse inflammatory macrophages and human peripheral blood monocytes were also used to confirm the results obtained with the cell line. Mouse inflammatory macrophages were obtained by the intraperitoneal injection of $3 \mathrm{ml}$ of a $3 \%$ thioglycolate 
(Sigma-Aldrich, USA) solution in distilled water. Three days after the injection, peritoneal macrophages were collected, washed three times with HBSS and resuspended in complete RPMI. The peritoneal exudates obtained using this process contained more than $70 \%$ of cells with macrophage characteristics, as evaluated by flow cytometry using forward and side scatter. Human monocytes were isolated from buffy coats obtained from normal volunteers by the Bahia State Haematology and Haemotherapy Foudation (HEMOBA). Cells were suspended in RPMI 1640 (Sigma-Aldrich, USA) and centrifuged over a Ficoll-Paque plus (Amersham-Pharmacia Biotech, AB, Sweden) solution, followed by a slightly hyperosmolar (density $=1.070$ ) Percoll (Amersham-Pharmacia Biotech, AB, Sweden) gradient, as previously described (de Almeida et al., 2000). The cells were washed in HBSS (Sigma-Aldrich, USA) and resuspended in complete RPMI. This fractionation protocol yielded a $87 \%$ pure monocyte population, as judged by morphology and flow cytometry. J774 cells, peritoneal exudate cells and peripheral blood monocytes were resuspended at $2 \times 10^{6}$ cells $/ \mathrm{ml}$ in complete RPMI and cultured overnight in non-adherent polypropylene tubes at $37^{\circ} \mathrm{C}$ and at $5 \% \mathrm{CO}_{2}$ atmosphere.

\subsection{Adhesion assay}

Fixed tissue sections were incubated with HBSS containing $4 \mathrm{mg} / \mathrm{ml}$ bovine serum albumin (BSA, Sigma-Aldrich, USA), for $20 \mathrm{~min}$ at room temperature. They were then washed with PBS before co-incubation with cell suspension. The cells were washed twice in HBSS and resuspended in HBSS containing 10\% FBS. Aliquots of $100 \mu \mathrm{l}$ of the cell suspension were placed over the tissue sections. A $10-\mathrm{mm}$ diameter circle was drawn around the section with a non-toxic marker pen (Pap Pen, Zymed Laboratories, USA) to prevent the free flow of cell suspension over the whole slide. After a 30-min incubation, the sections were washed three times with PBS to remove non-adherent cells and fixed for 10 min with $2 \%$ glutaraldehyde in PBS, at room temperature. After washing with distilled water the sections were stained with haematoxylin-eosin, and examined under light microscopy. Sections were initially examined to identify the areas of well-characterized inflammation. These areas were assigned for quantification of adhered cells. This measurement was performed using a Leica Quantimet Q500MC image analyser (Leica, Cambridge, UK).

\subsection{Removal of divalent cations from the mononuclear phagocyte-connective tissue adhesion assay}

J774 cells were cultured overnight in non-adherent tubes, washed with $\mathrm{Ca}^{2+}$ - and $\mathrm{Mg}^{2+}$-free HBSS and resuspended in HBSS containing $2 \mathrm{mM}$ of EDTA (Sig-
ma-Aldrich, USA) for $5 \mathrm{~min}$ at $4{ }^{\circ} \mathrm{C}$. They were then washed and resuspended in HBSS containing 10\% FBS alone or with either $2 \mathrm{mM}$ EDTA or $2 \mathrm{mM} \mathrm{MnCl}_{2}$ (Sigma-Aldrich, USA).

\subsection{Inhibition of cell adhesion with peptides and anti- integrin antibodies}

J774 cells and tissue sections were pre-incubated with $25 \mu \mathrm{g} / 10^{6}$ cells of antibodies against $\beta_{2}$ (game $46, \mathrm{IgG} 1, \kappa$ isotype) and $\alpha_{4}(\mathrm{R} 1 / 2, \operatorname{Ig} G 2 \mathrm{~b}, \kappa$ isotype), both from Pharmingen (USA) and with $1 \mathrm{mg} / \mathrm{ml}$ of peptides containing the CS-1 sequence of fibronectin (DELPQLVTL PHPNLHGPEILDVPST) and the RGD sequence common to many connective matrix components (RGDS, Sigma-Aldrich, USA). As control, $25 \mu \mathrm{g} / 10^{6}$ cells of isotype-matched antibodies R3-34 (IgG1, $\kappa$ isotype) and $\mathrm{R} 35-38$ (IgG2b, $\kappa$ isotype), both from Pharmingen and $1 \mathrm{mg} / \mathrm{ml}$ of the truncated peptides CS1t (DELPQL VTLPHPNLHGPPVTSELID) and RGDt (GRGES) were used. CS1 and the truncated versions of the peptides were kindly supplied by Dr. Antonio Oliveira dos Santos, (Amgen Research Institute, Canada).

\subsection{Cell activation}

J774 cells were cultured overnight in complete RPMI alone or containing different concentrations of bacterial lypopolysaccharide (LPS, Sigma-Aldrich, USA). The cells subjected to the different treatments were washed and used in the adhesion assays.

\subsection{Infection of mononuclear phagocytes by Leishmania and by Mycobacterium}

Leishmania braziliensis (MHOM/BR/3456); Leishmania amazonensis (Leila strain, MHOM/BR88/BA-125), and Lesihmania chagasi (MHOM/BR2000/Merivaldo2 strain) were grown in vitro using Schneider's insect medium (Sigma-Aldrich, USA) containing $20 \%$ of fetal bovine serum (Gibco-BRL, USA) (Teixeira et al., 2002). Mycobacterium fortuitum was isolated from naturally infected C57BL/6 mice and characterized by polymerase chain reaction as previously described (Da Silva et al., 2002), then $10^{8}$ bacilli were inoculated intravenously in Nude nu/nu mice to obtain virulent transparent variants. After 30 days of infection bacteria were harvested from liver and spleen of infected Nude nu/nu mice and grown on Middlebrook $7 \mathrm{H} 10$ agar plates (Difco Laboratories, USA) supplemented with $10 \%$ oleic acid-albumin-dextrose-catalase (Difco Laboratories). Aliquots of Mycobacterium were frozen at $-70^{\circ} \mathrm{C}$. For infection, the frozen samples were quickly thawed, vortexed, passed several times through a 25-gauge tuberculin needle to make single bacterial cell suspension. Leishmania promastigotes or Mycobacterium were 
washed three times in HBSS, and incubated overnight with $\mathrm{J} 774$ cells in non-adherent tubes at $37^{\circ} \mathrm{C}, 5 \% \mathrm{CO}_{2}$. As a control, $3 \mu \mathrm{m}$ latex beads (Sigma-Aldrich, USA) were used. Ten microorganisms or latex particles per J774 cell were used in each experiment. To determine the percentage of infected cells, cytospin preparations of J774 cell cultures were fixed with $2.5 \%$ glutaraldehyde or with methanol, were air dried, stained with ZiehlNeelsen (Crowle and May, 1981) or Wright stains and examined by light microscopy. At least 500 mononuclear cells were counted in triplicates to determine the infection rate.

\subsection{Investigation of expression of surface molecules}

Cells were analyzed for surface expression of CD-11b (Mac-1), CD-49d ( $\alpha 4$-integrin), CD-62L (L-selectin) and CD-106 (VCAM-1). All the antibodies were fluorescein conjugates (clones M1/70, 9C10/MFR4.B, MEL-14, 429/MVCAM.A, respectively) obtained from Pharmingen. J774 cells, non-infected or after 18-20 h of infection with Leishmania, were prepared for analysis by resuspension in PBS containing 1\% bovine serum albumin and $0.05 \%$ sodium azide (PBS-BSA) and blocked with rat immunoglobulin $(20 \mu \mathrm{g} / \mathrm{ml})$ and $10 \%$ FBS for $30 \mathrm{~min}$ on ice. The cells were then incubated with labeled antibodies, corresponding isotype controls (fluoresceinconjugated rat immunoglobulins clones A95-1 and R3595, both from Pharmingen) or diluent, for $30 \mathrm{~min}$. The cells were washed and fixed with $1 \%$ paraformaldehyde in PBS and analyzed with a FACS flow cytometer and CellQuest software (Becton-Dickinson). At least 5000 events were analyzed per sample.

\subsection{Expression and analysis of results}

The adhesion assays were always performed in at least triplicate using serial sections. They are expressed as means \pm SEM of the number of cells adhered to an area of the section measured in square micrometer. The statistical significance of the differences between groups was assessed using the two-tailed $t$ test, or one-way ANOVA (more than two groups), with critical level of significance at $p \leqslant 0.05$. When the $F$ test was found significant, the difference between two groups was identified using the Student-Newman-Keuls test. Trends were measured using Pearson's correlation coefficient ( $r$ ) (Glantz, 1997).

\section{Results}

\subsection{Determination of optimal experimental conditions}

In this part of the study, we tested fixatives, preservation state of tissue sections after storage and agitation in mononuclear phagocyte adhesion, using tissue sections containing normal, and inflamed areas. The glutaraldehyde fixation of inflammatory air pouches, as proposed by Stamper and Woodruff (Stamper and Woodruff, 1976) for spleen, lead to a widespread adherence of cells all over the section and even to the gelatin film used as substrate. Such non-specific binding was abolished with cold acetone fixation. A slight decrease in cell adhesion was observed when agitation was excluded or when the slides containing the tissue sections kept for $24 \mathrm{~h}$ at $-70^{\circ} \mathrm{C}$ before using for adhesion assays. This change was never statistically significant. The number of adherent cells increased with the amount of added cells into the $78.5 \mathrm{~mm}^{2}$ area, between $2.0 \times 10^{5}$ and $1.0 \times 10^{6}$ cells (Pearson $r=0.7546, p=0.002$ ), reaching a plateau. Varying the incubation temperature between 25 (room temperature) and $37^{\circ} \mathrm{C}$ did not change the cell adhesion to tissue sections. Hence, the subsequent experiments were performed using tissue sections obtained on the day of the experiment and fixed with acetone, the adhesion assays were performed at room temperature, under agitation, and the sections were overlaid with cell suspensions containing $5.0 \times 10^{5}$ $1.0 \times 10^{6}$ cells. Under such conditions, J774 cells

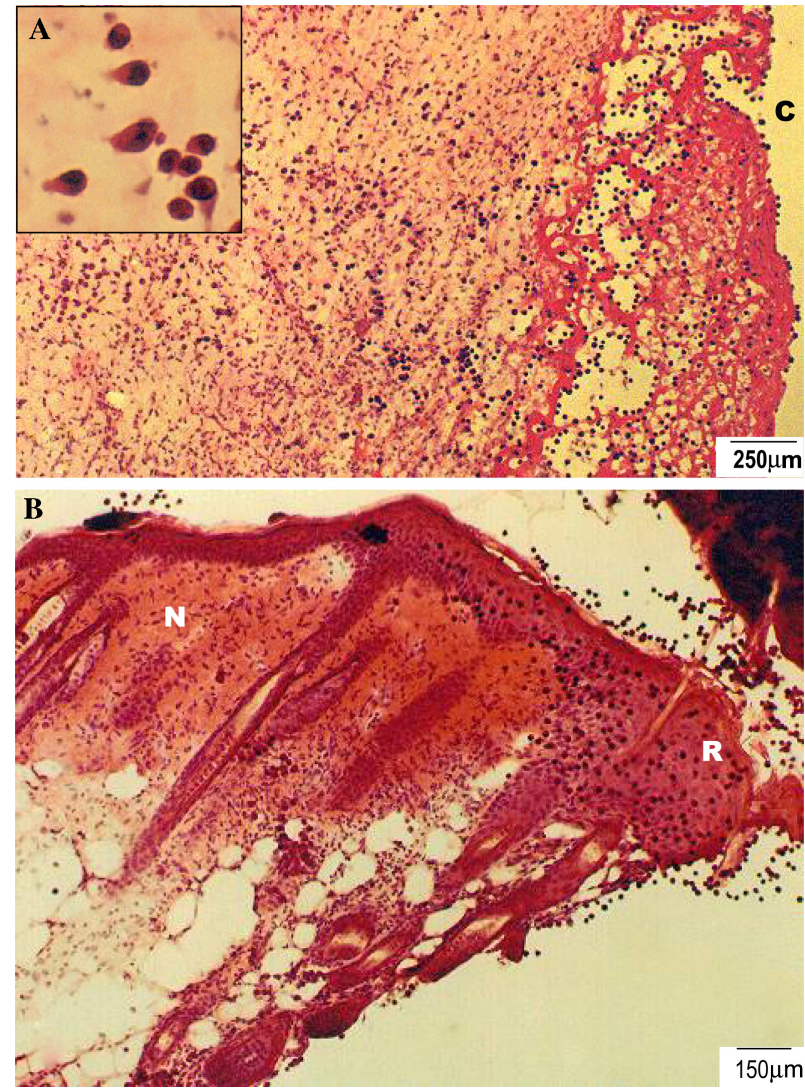

Fig. 1. J774-cell adhesion to connective tissue: (A) Inflammatory air pouch, $(\mathrm{C}$, cavity): cell adhesion to inflamed tissue and $(\mathrm{B})$ to the regenerating epithelium $(\mathrm{R})$ and normal skin $(\mathrm{N})$. Cells adhere and spread their cytoplasm (insert). 
adhered to inflammatory sites around the air pouch (Fig. 1A) or to the regenerating epithelial cells in the epidermis in the areas of lesion (Fig. 1B), with minimal adherence to normal tissues. The cells were firmly adhered and spread their cytoplasm on the inflammatory connective tissue (Fig. 1 insert).

\subsection{In vitro adhesion of mononuclear phagocyte to connective tissue is divalent cation dependent}

Treatment with EDTA decreased by $58 \pm 13 \%$ in average $(p=0.0241 ; t$ test $)$, and in some experiments almost completely abolished (up to $89 \%$ inhibition, $p<0.001) \mathrm{J} 774$ cell adhesion to inflammatory tissue (Fig. 2). The EDTA effect was completely reversed by carrying out the adhesion assay in the presence of $\mathrm{Mn}^{2+}$ (Fig. 2). In fact, in some experiments cell adhesion was higher in presence of $\mathrm{Mn}^{2+}$ than with $\mathrm{Ca}^{2+}$ and $\mathrm{Mg}^{2+}$, but such difference was not always statistically significant.

\subsection{Mononuclear phagocyte adhesion to inflamed con- nective tissue in vitro depended on integrins}

The incubation of cells and sections with RGD or CS-1 peptides alone had no effect in $\mathbf{J} 774$ cell adhesion. Combined, RGD and CS-1 peptides reduced, by $58 \pm 2 \%$ in average, $\mathrm{J} 774$ cell adhesion to inflamed tissue

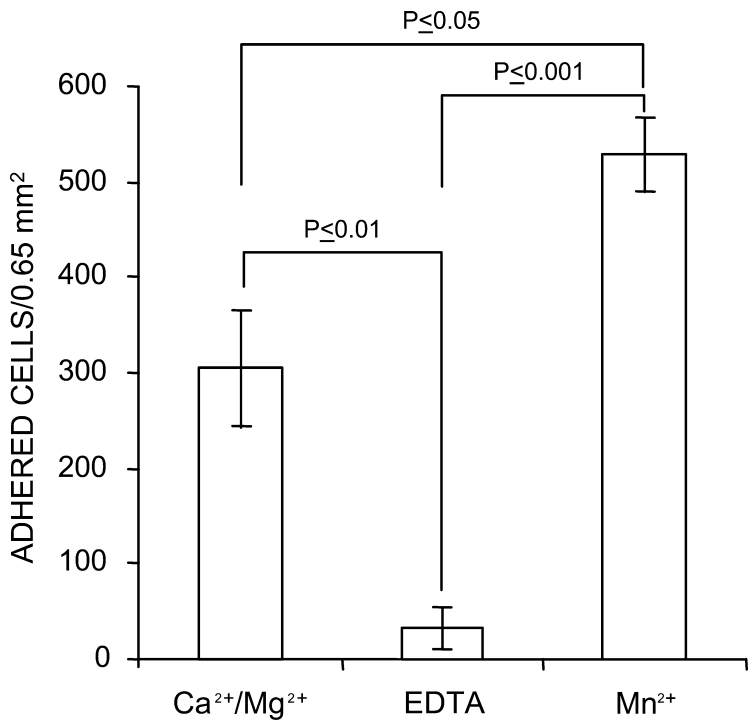

Fig. 2. J774 cell adhesion to inflamed connective tissue in presence of divalent cations: medium containing $0.5 \mathrm{mM}$ of $\mathrm{CaCl}_{2}$ and $0.5 \mathrm{mM}$ of $\mathrm{MgCl}_{2}\left(\mathrm{Ca}^{2+} / \mathrm{Mg}^{2+}\right)$ or $1 \mathrm{mM}$ of $\mathrm{MnCl}_{2}\left(\mathrm{Mn}^{2+}\right)$; or in absence of divalent cations: in presence of $5 \mathrm{mM}$ EDTA (EDTA). The data are representative of nine experiments. Vertical bars represent means $\pm \mathrm{SE}$ of the number of adhered cells per area for the different treatments, performed in quadruplicate. The statistical significance values of the differences between the results are shown on top of horizontal lines joining columns that represent them.
( $p<0.05$, ANOVA followed by SNK test). The RGDt and CS-1t truncated peptides, either isolated or mixed, had no significant effect in $\mathbf{J} 774$ cell adhesion to inflamed tissue (Fig. 3A). Antibodies against $\alpha 4$ - and $\beta 2$-integrins had no effect on $\mathbf{J} 774$ cell adhesion to inflamed skin when tested separately. Combined, anti- $\beta 2$ with anti- $\alpha 4$ antibodies and/or CS-1 peptide reduced from 49.5 to $77.4 \%(p<0.01$, ANOVA $)$ the $\mathbf{J} 774$ cell adhesion to connective tissue (Fig. 3B).

\subsection{J774 cell activation by LPS increased their adhesion to inflammatory tissue in vitro}

The J774 cell treatment for $18-20 \mathrm{~h}$ with LPS increased by $10-64 \%$ cell adhesion to inflamed connective tissue ( $p<0.05$, Fig. 4$)$. The LPS effect was dose-dependent and reached a plateau at the concentration of $0.1 \mu \mathrm{g} / \mathrm{ml}$ (not shown). A decrease in adherence and also
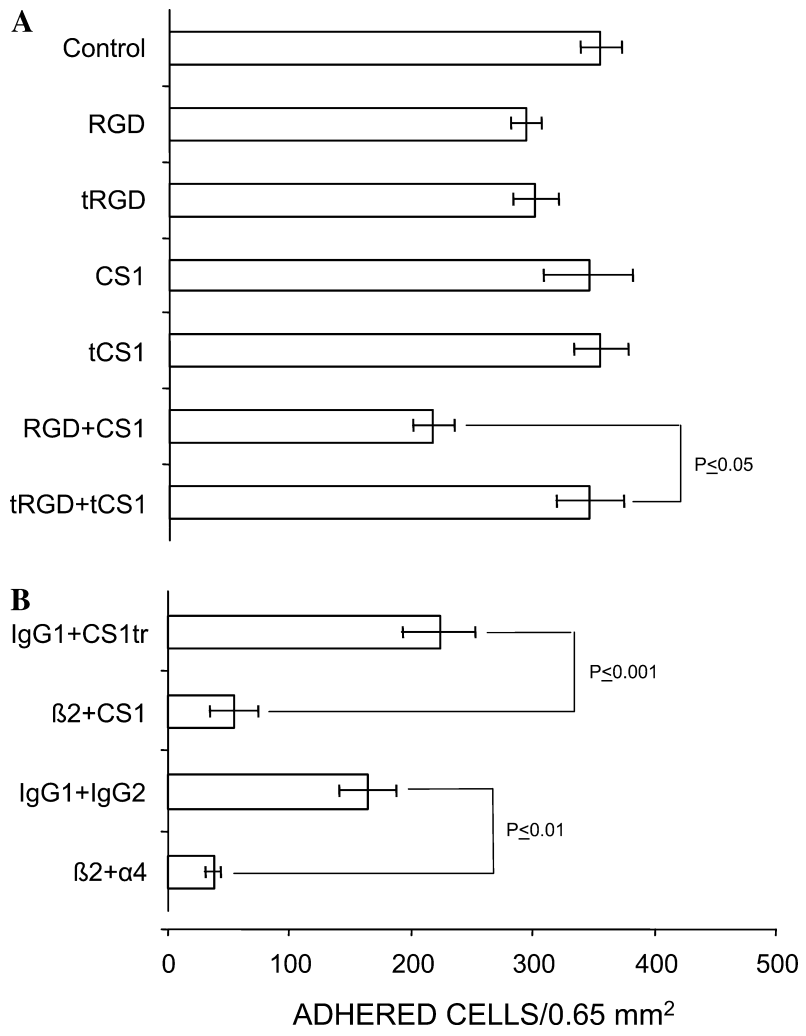

Fig. 3. Effect of the presence of RGD and CS1 peptides or anti-integrin blocking antibodies in the J774-cell adhesion to inflamed connective tissue (graphics A and B represent two different experiments). (A) Peptides were tested separately (RGD or CS1) or combined $(\mathrm{RGD}+\mathrm{CS} 1)$. RGDt is a truncated RGD peptide and CS1t is a truncated CS1 peptide. (B) Antibody against $\beta 2$ integrin with antibody against $\alpha 4$ integrin $(\beta 2+\alpha 4)$ or with CS1 peptide $(\beta 2+\mathrm{CS} 1)$. IgG1 and $\mathrm{IgG} 2$ are isotype matched control immunoglobulins. Data are representative of three experiments. Horizontal bars represent means $\pm \mathrm{SE}$ of experiments performed in triplicate. The statistical significance values of the differences between the results are shown on the side of the vertical lines joining bars that represent them. 


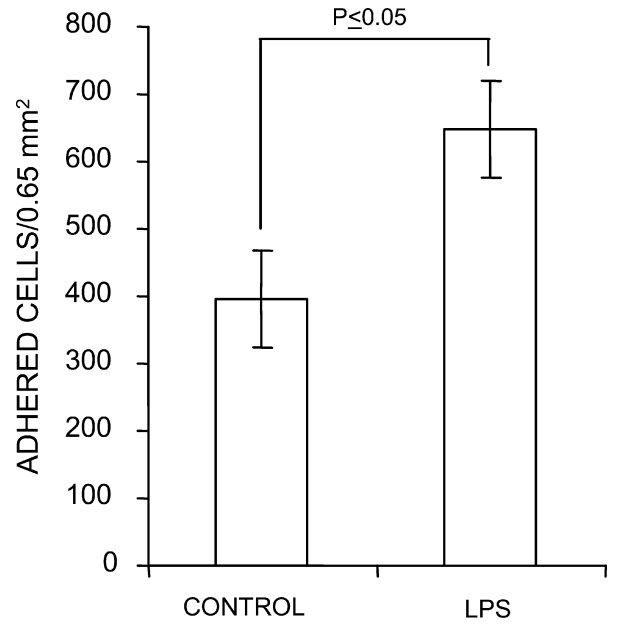

Fig. 4. Effect of $\mathbf{J} 774$ cells activation with LPS in their adherence to inflamed connective tissue. The cells were incubated overnight with medium alone (Control) or containing $1 \mu \mathrm{g} / \mathrm{ml}$ of LPS (LPS). They were then washed and used in adhesion assay as described in the Material and methods. The data are representative of three experiments. Vertical bars represent means $\pm \mathrm{SE}$ of the number of adhered cells per area for the different treatments, performed in quadruplicate. The statistical significance values of the differences between the results are shown on top of horizontal lines joining columns that represent them.

of cell viability was observed when concentrations above $10 \mu \mathrm{g} / \mathrm{ml}$ of LPS were used.

\subsection{Leishmania infection inhibited mononuclear phago- cyte adhesion to inflamed connective tissue}

Infection with different Leishmania species (L. amazonensis, L. braziliensis, or L. chagasi) significantly inhibited $(58+22 \%, p=0.05$, ANOVA, and SNK test) J774 cell adhesion to inflamed tissue (Figs. 5A-D). Cell adhesion did not change with overnight incubation with $3 \mu \mathrm{m}$ latex beads or after $\mathbf{J} 774$ cell infection with M. fortuitum (Fig. 6). Similar inhibition of cell adhesion by Leishmania infection was observed with thioglycolate induced mouse peritoneal macrophages $(50-85 \%$ inhibition, Fig. 7A) or with human peripheral blood monocytes (23-51\% inhibition, Fig. 7B).

\subsection{Adhesion molecules expression on Leishmania-in- fected $\mathrm{J774}$ cells}

No significant change was observed in Mac-1, VLA4, L-selectin or VCAM-1 expressions after $18-20 \mathrm{~h}$ of infection with L. braziliensis (Fig. 8).

\subsection{Manganese partially reverted the inhibition of $\mathbf{J 7 7 4}$ cell adhesion induced by Leishmania infection}

Since no significant changes on cell surface expression of adhesion molecules in the group of cells infected with
Leishmania was observed, we treated these cells with $\mathrm{Mn}^{2+}$, to see if a state of high affinity for their receptor could be induced in the integrins expressed on the surface of these cells resulting in an increase in adherence to connective tissue. Treatment of Leishmania-infected $\mathrm{J} 774$ cells with $2 \mathrm{mM}$ of $\mathrm{MnCl}_{2}$ partially restored their adherence to inflamed connective tissue, to the levels of control non-infected cells (Fig. 9).

\section{Discussion}

In this work, we developed an assay for studying mononuclear phagocyte interactions with connective tissue based on the assay previously described by Stamper and Woodruff (1976). Three bodies of observations made in the study support the hypothesis that the model described herein mimics specific interactions between leukocytes and connective tissue observed in vivo: first, the adherence of $\mathbf{J} 774$ cells to the tissue sections at room temperature was not indiscriminate: it preferentially occurred on the inflamed connective tissue. In inflamed areas, changes are induced in the connective tissue (Santos et al., 1994), resulting in an increase in the number and redistribution of adhesion sites, and in the release of chemoattractants for inflammatory cells (Loike et al., 1999; Schor et al., 2000). In this study, we used inflammatory air pouches after three to four days of induction. At this stage, a neutrophiland macrophage-rich inflammatory infiltrate was evident in the lesion. This finding indicates that adhesion sites and chemoattractants for mononuclear phagocytes migration were also present. The presence of both normal and inflamed tissues in these sections allowed a clear distinction between areas with different capabilities of supporting cell migration and such finding was reflected on the preferential adhesion of mononuclear phagocytes to inflamed areas in the in vitro assay.

The second body of evidence for the specificity of the adhesion reported herein comes from the finding that adhesion of $\mathbf{J} 774$ cells to the inflamed connective tissue in vitro was divalent cation dependent: it significantly decreased in presence of EDTA and was restored by addition of $\mathrm{Ca}^{2+}$ and $\mathrm{Mg}^{2+}$ or $\mathrm{Mn}^{2+}$. Various leukocyte adhesion pathways are dependent on calcium or magnesium for their function (Carlos and Harlan, 1994). Integrins have different requirements of $\mathrm{Ca}^{2+}$ and $\mathrm{Mg}^{2+}$ for clustering (van Kooyk et al., 1994) or increasing their affinity for their receptors (Takagi and Springer, 2002; van Kooyk et al., 1994). Manganese can induce in some integrins an even higher affinity state for their receptor than that observed in presence of $\mathrm{Mg}^{2+}$ (Takagi and Springer, 2002). In fact, in the experiments presented herein, $\mathrm{Mn}^{2+}$ not only restored the adherence of J774 cells to connective tissue, but also induced in some experiments levels of cell adhesion higher than the 

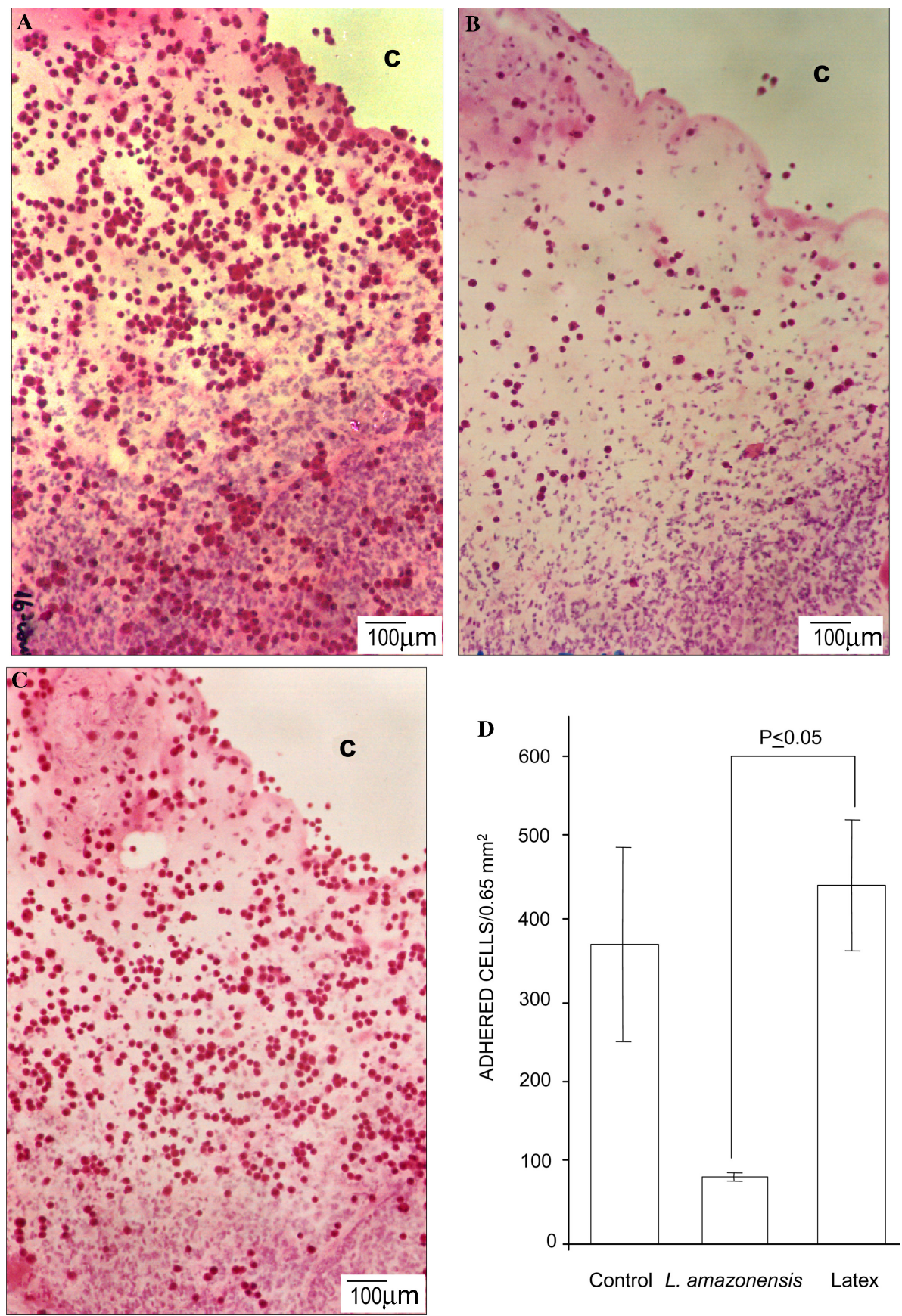

Fig. 5. Effect of Leishmania infection in J774-cell adhesion to inflamed connective tissue (Inflammatory air pouch; C, cavity): the cells were incubated overnight with medium alone (A) or with L. amazonensis (B) or with 3- $\mu \mathrm{m}$ latex beads (C), washed and used in the adhesion assay as described in the Material and methods. The graph (D) represents a quantitative analysis of J774-cell adhesion after the different treatments. Data are representative of six experiments. Vertical bars represent means $\pm \mathrm{SE}$ of experiments performed in quadruplicate. The statistical significance values of the differences between the results are shown on the side of the vertical lines joining bars that represent them.

adherence observed in presence of control medium, containing $\mathrm{Ca}^{2+}$, and $\mathrm{Mg}^{2+}$. Although the participation of other $\mathrm{Ca}^{2+}$-dependent adhesion systems, such as $\mathrm{C}$ lectins (Gabius, 1997) can not be excluded, the characteristics of the cell adherence observed in this work, such as high strength (the cells were not displaced even after three washes under agitation), and cytoplasm spread by the adhered cells, suggested an integrin participation in the process. In fact, the adherence of J774 cells to inflamed tissue was inhibited by anti-integrin antibodies and by peptides (CS-1 and RGD) bearing sequences corresponding to the binding sites for integrins in connective matrix components, a fact that constitutes a third type of evidence for the specificity of the cell ad- 

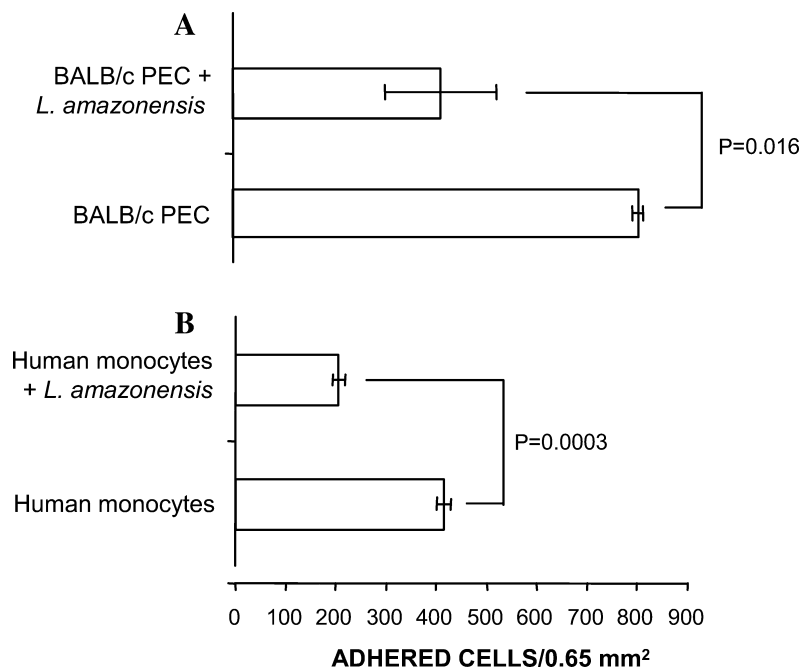

Fig. 6. Effect of Leishmania infection in the adherence of (A) BALB/c mice thioglycolate-induced peritoneal exudate cells (BALB/c PEC) or of (B) human peripheral blood monocytes to inflamed connective tissue. The cells were incubated overnight with $L$. amazonensis (BALB/c $\mathrm{PEC}+L$. amazonensis or Human monocytes $+L$. amazonensis), with Latex particles (BALB/c PEC + latex) or with medium alone (BALB/c PEC or Human monocytes), washed and used in the adhesion assay as described in the Material and methods. Horizontal bars represent means \pm SE. Graphics A and B represent two different experiments performed in quadruplicate (BALB/c PEC) or triplicate (Human monocytes) and repeated twice with similar results. The statistical significance values of the differences between the results are shown on the side of the vertical lines joining bars that represent them.

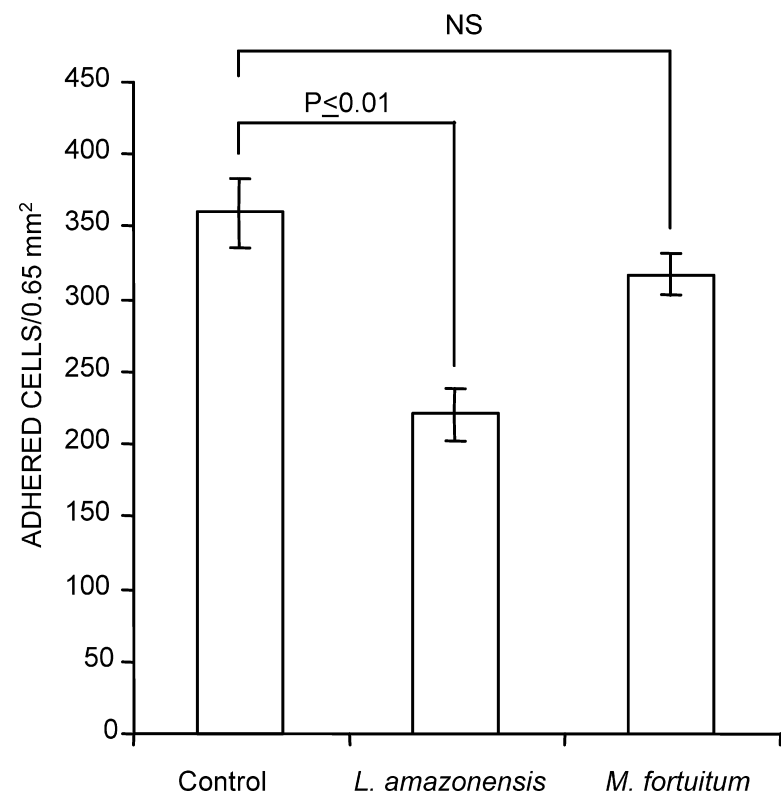

Fig. 7. Infection with Leishmania and not with Mycobacteria reduces J774 cell adhesion to inflamed tissue: J774-cells were incubated overnight with $L$. amazonensis (L. amazonensis), with Mycobacterium frotuitum (M. fortuitum) or with medium alone (Control), washed and used in the adhesion assay as described in the Material and methods. Vertical bars represent means $\pm \mathrm{SE}$ of three experiments performed in triplicate. The statistical significance values of the differences between the results are shown on top of horizontal lines joining columns that represent them. herence. The fact that only combinations of RGD and CS- 1 peptides and of anti- $\beta 2$ and anti- $\alpha 4$ antibodies significantly reduced the adherence of $\mathbf{J} 774$ cells to inflamed tissue indicate that both $\beta 1$ and $\beta 2$ integrins participate in the process of cell adhesion. The participation of these integrins, both in leukocyte adhesion and migration into inflammatory sites has been demonstrated in many works, summarized in a series of good reviews (Carlos and Harlan, 1994; Schor et al., 2000; Springer, 1995). $\beta 1$ Integrins are considered the main leukocyte receptors for connective matrix components and $\beta 2$ integrins such as Mac-1 and LFA-1, which also interact with cell receptors, play an important role in leukocyte migration into inflammatory sites (Loike et al., 1999).

The level of cell adhesion inhibition observed in this work with antibodies or peptides combinations were never complete. Partial blockage of cell adhesion is a common finding in many adhesion systems (Malawista and de Boisfleury Chevance, 1997), even when less complex substrates are used (Male et al., 1994). Although the possibility of some bridge formation between antibodies and their receptors on the cells and in the tissue section (the experiments were performed using complete antibody molecules) can not be excluded, the fact that the results obtained with antibodies were not substantially different from those obtained with peptides suggests that other receptors, besides the integrins tested in these experiments, may be involved in the adherence of cells to the inflamed tissue. In fact, Malawista and Chevance (Malawista and de Boisfleury Chevance, 1997) have shown that non-divalent cation-dependent pathways, not yet identified, are involved in leukocyte adhesion with connective tissue.

As shown herein, J774 cell activation with LPS increases its adherence to inflamed tissue. This finding concurs with the classical observation of inhibition of macrophage migration following activation (Weiser et al., 1985). Surprisingly, our experiments using intracellular pathogens revealed a more complex pattern of mononuclear phagocyte-connective tissue interaction. Leishmania infection decreased the $\mathrm{J} 774$ cell, peritoneal inflammatory macrophage or human monocyte adhesion to inflamed connective tissue in a way that was not dependent only on phagocytosis, since control cells incubated with 3- $\mu \mathrm{m}$ latex beads did not have their adherence to inflamed tissue affected. Such change in adhesion by Leishmania infection may involve specific mechanisms trigged by the parasite infection, since it was not observed in cells infected with M. fortuitum. The observations that the reduction in the levels of $\mathrm{J} 774$ cells adhesion was not associated with a decrease in the expression of the adhesion molecules potentially involved in the process, and that $\mathrm{Mn}^{2+}$ substantially restored the adherence of infected cells to inflamed tissue, suggest that mechanisms regulating integrin function (Hogg 
A
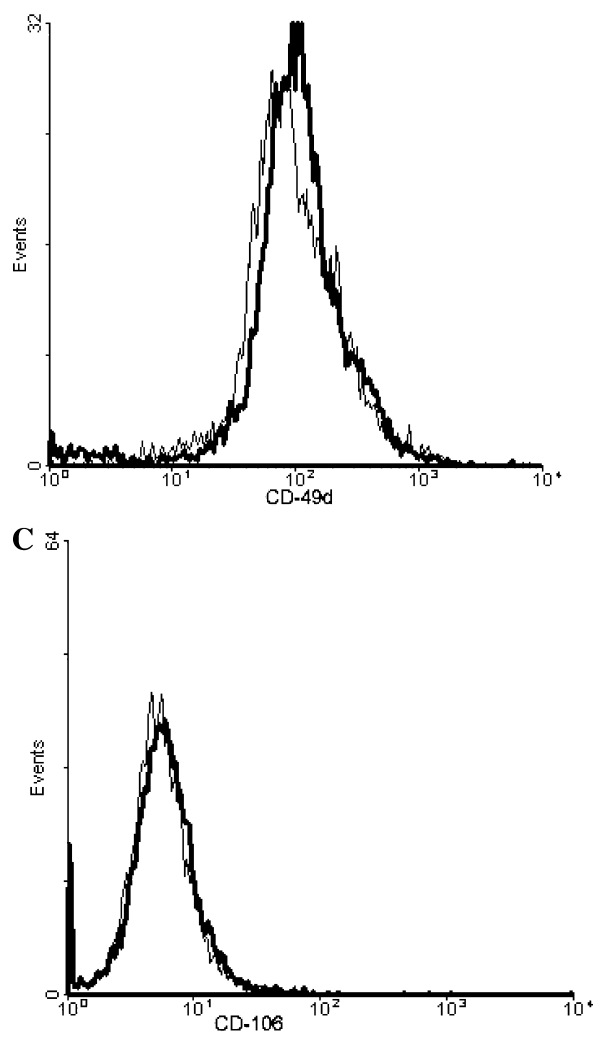

B

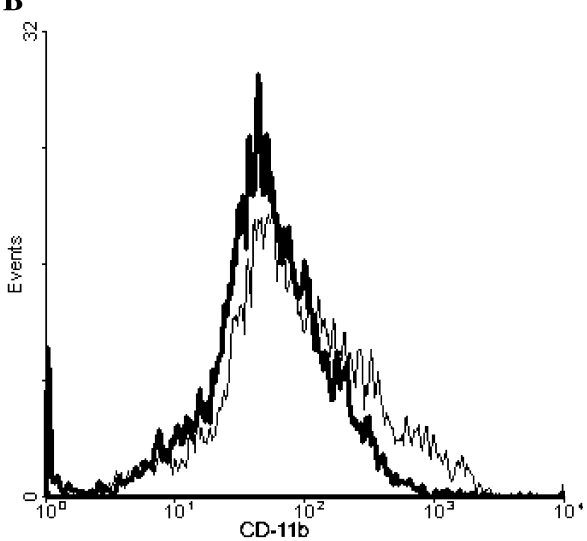

D

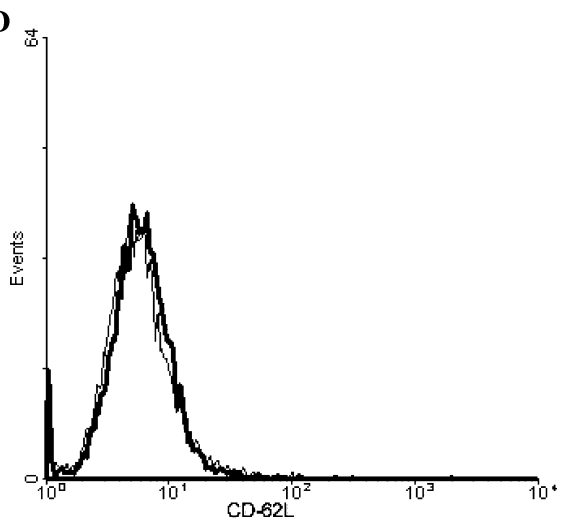

Fig. 8. Effect of Leishmania infection in J774 cell expression of (A) CD49d (VLA-4), (B) CD11b (Mac-1), (C) CD106 (VCAM-1), and (D) CD62-L (L-selectina). J774 cells were incubated overnight with medium alone or with L. amazonensis. The expression of the adhesion molecules was determined using the antibodies M1/70 (Mac-1), 9C10 (VLA-4), MEL-14 (L-Selectin), and 429 (VCAM-1). The thin line represents expression in noninfected cells and thick lines represent expression Leishmania-infected cells. The data are representative of three independent experiments.

et al., 2002) are altered in Leishmania infected mononuclear phagocytes. In fact, Leishmania infection changes the intracellular calcium homeostasis in macrophages, inhibiting G-protein-dependent signal transduction and cell activation by chemotactics (Olivier et al., 1992). It is possible that a similar mechanism of interference with intracellular signaling results in impairment of integrin regulation by inside-out signs (Hogg et al., 2002) and, consequently, cell adhesion to connective tissue. Further studies on the molecular mechanisms involved in modulation of mononuclear phagocyte adherence by Leishmania infection are now under way in our laboratory.

What would be the physiopathological significance of the reduced adherence of Leishmania-infected mononuclear phagocytes to connective tissue? Evidence that emerged from studies with Leishmania infection shows that, after inoculation into the dermis, a fraction of the parasites are carried over to the regional lymph nodes, possibly in the interior of dendritic cells derived from Langerhans (Moll et al., 1993) or other circulating mononuclear phagocyte (Muraille et al., 2003; Randolph et al., 1999). In addition, Leishmania have been observed in the interior of phagocytic cells circulating in the blood (Liarte et al., 2001). These findings indicate that, after being infected by Leishmania in the tissues, mononuclear phagocytes can emerge in the blood or lymph. Detachment is the first step in the emigration of cells from one site to another. It is therefore possible that the reduction of phagocytic cell adhesion to connective tissue induced by Leishmania infection play a critical role in parasite dissemination, by causing parasite movements throughout the organism inside phagocytic cells, spreading the infection to different tissues (lymph nodes, mucosae, spleen, and liver). Further studies are necessary to confirm this hypothesis and to identify the populations of mononuclear phagocytes involved and the mechanisms modulating their adherence after Leishmania infection. The in vitro model of cell adhesion described herein may be helpful in these studies. This model may also be adapted to test functional aspects of interactions between mononuclear phagocytes and other inflammatory cells with connective tissue in a variety of diseases in which such interactions play a role in defense and the development of lesions. 


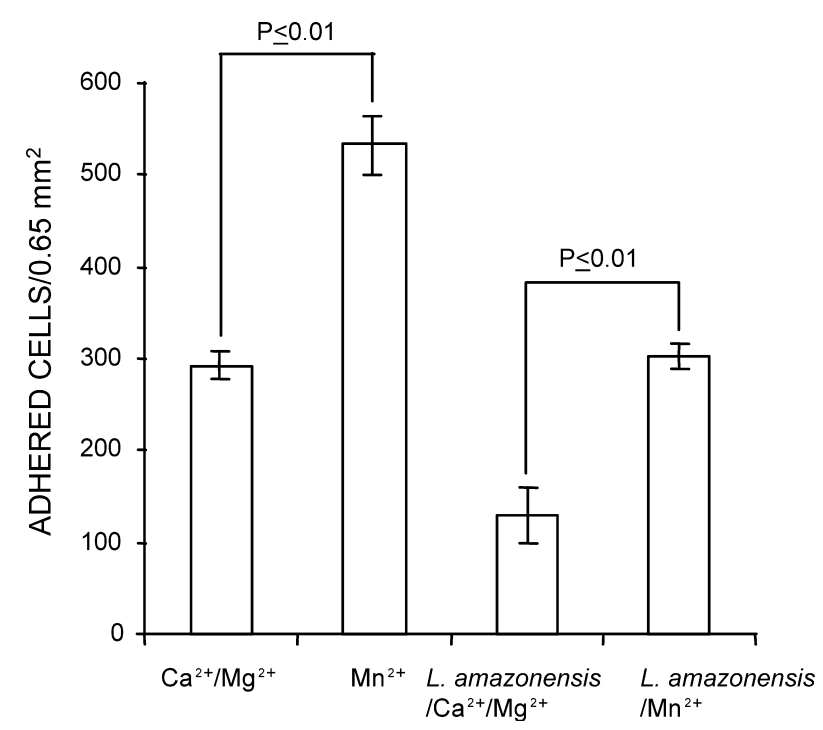

Fig. 9. Effect of calcium and magnesium replacement by manganese in the adhesion of Leishmania-infected J774-cell adhesion to inflamed connective tissue. J774 cells were incubated overnight with medium alone or with $L$. amazonensis. They were then incubated with EDTA, washed, resuspended in medium containing $0.5 \mathrm{mM}$ of $\mathrm{CaCl}_{2}$ and $0.5 \mathrm{mM}$ of $\mathrm{MgCl}_{2}\left(\mathrm{Ca}^{2+} / \mathrm{Mg}^{2+}\right.$ and L. amazonensis $\left./ \mathrm{Ca}^{2+} / \mathrm{Mg}^{2+}\right)$ or $1 \mathrm{mM} \mathrm{MnCl}{ }_{2}\left(\mathrm{Mn}^{2+}\right.$ and L. amazonensis $\left./ \mathrm{Mn}^{2+}\right)$. The data are representative of three independent experiments. Vertical bars represent means $\pm \mathrm{SE}$ of three experiments performed in triplicate. The statistical significance values of the differences between the results are shown on top of horizontal lines joining columns that represent them.

\section{Acknowledgments}

This work was supported by the Oswaldo Cruz Foundation (PAPES II, Grant No. 250.250.320) and Brazilian National Research Council, (CNPq, Grant No. 52629/96-5). We are indebted to Dr. Lain Pontes de Carvalho and to Dr. Johan Van Weyenbergh (both from Oswaldo Cruz Foundation) for their careful revision and suggestions to the text.

\section{References}

Barbe, E., Huitinga, I., Dopp, E.A., Bauer, J., Dijkstra, C.D., 1996. A novel bone marrow frozen section assay for studying hematopoietic interactions in situ: the role of stromal bone marrow macrophages in erythroblast binding. J. Cell Sci. 109 (Pt. 12), 2937-2945.

Carlos, T.M., Harlan, J.M., 1994. Leukocyte-endothelial adhesion molecules. Blood 84, 2068-2101.

Cavanagh, L.L., Von Andrian, U.H., 2002. Travellers in many guises: the origins and destinations of dendritic cells. Immunol. Cell Biol. $80,448-462$.

Chakravorty, S.J., Howie, A.J., Cockwell, P., Adu, D., Savage, C.O., 1999. T lymphocyte adhesion mechanisms within inflamed human kidney: studies with a Stamper-Woodruff assay. Am. J. Pathol. 154, 503-514.

Coleman, N., Stanley, M.A., 1994. Characterization and functional analysis of the expression of vascular adhesion molecules in human papillomavirus-related disease of the cervix. Cancer 74, 884-892.
Crowle, A.J., May, M., 1981. Preliminary demonstration of human tuberculoimmunity in vitro. Infect. Immun. 31, 453-464.

Da Silva, T.R., De Freitas, J.R., Silva, Q.C., Figueira, C.P., Roxo, E., Leao, S.C., De Freitas, L.A., Veras, P.S., 2002. Virulent mycobacterium fortuitum restricts NO production by a gamma interferon-activated $\mathbf{J} 774$ cell line and phagosome-lysosome fusion. Infect. Immun. 70, 5628-5634.

de Almeida, M.C., Silva, A.C., Barral, A., Barral Netto, M., 2000. A simple method for human peripheral blood monocyte isolation. Mem. Inst. Oswaldo Cruz 95, 221-223.

dos Santos, W.L., Rahman, J., Klein, N., Male, D.K., 1996. Control of lymphocyte adhesion to brain and aortic endothelium: ICAM-1, VCAM-1 and negative charge. J. Neuroimmunol. 66, 125-134.

Gabius, H.J., 1997. Animal lectins. Eur. J. Biochem. 243, 543-576.

Glantz, S.A., 1997. Primer of Bio-Statistics, fourth ed. McGraw-Hill, New York. 1-473.

Grober, J.S., Bowen, B.L., Ebling, H., Athey, B., Thompson, C.B., Fox, D.A., Stoolman, L.M., 1993. Monocyte-endothelial adhesion in chronic rheumatoid arthritis. In situ detection of selectin and integrin-dependent interactions. J. Clin. Invest. 91, 26092619.

Hogg, N., Henderson, R., Leitinger, B., McDowall, A., Porter, J., Stanley, P., 2002. Mechanisms contributing to the activity of integrins on leukocytes. Immunol. Rev. 186, 164-171.

Liarte, D.B., Mendonca, I.L., Luz, F.C., Abreu, E.A., Mello, G.W., Farias, T.J., Ferreira, A.F., Millington, M.A., Costa, C.H., 2001. $\mathrm{QBC}$ for the diagnosis of human and canine American visceral leishmaniasis: preliminary data. Rev. Soc. Bras. Med. Trop. 34, 577-581.

Loike, J.D., Cao, L., Budhu, S., Marcantonio, E.E., El Khoury, J., Hoffman, S., Yednock, T.A., Silverstein, S.C., 1999. Differential regulation of betal integrins by chemoattractants regulates neutrophil migration through fibrin. J. Cell Biol. 144, 10471056.

Malawista, S.E., de Boisfleury Chevance, A., 1997. Random locomotion and chemotaxis of human blood polymorphonuclear leukocytes (PMN) in the presence of EDTA: PMN in close quarters require neither leukocyte integrins nor external divalent cations. Proc. Natl. Acad. Sci. USA 94, 11577-11582.

Male, D., Rahman, J., Pryce, G., Tamatani, T., Miyasaka, M., 1994. Lymphocyte migration into the CNS modelled in vitro: roles of LFA-1, ICAM-1 and VLA-4. Immunology 81, 366-372.

Mantovani, A., Sozzani, S., Locati, M., Allavena, P., Sica, A., 2002. Macrophage polarization: tumor-associated macrophages as a paradigm for polarized M2 mononuclear phagocytes. Trends Immunol. 23, 549-555.

Marlin, S.D., Springer, T.A., 1987. Purified intercellular adhesion molecule-1 (ICAM-1) is a ligand for lymphocyte function-associated antigen 1 (LFA-1). Cell 51, 813-819.

Matsushita, Y., Kitajima, S., Goto, M., Tezuka, Y., Sagara, M., Imamura, H., Tanabe, G., Tanaka, S., Aikou, T., Sato, E., 1998. Selectins induced by interleukin-1beta on the human liver endothelial cells act as ligands for sialyl Lewis X-expressing human colon cancer cell metastasis. Cancer Lett. 133, 151-160.

Moll, H., Fuchs, H., Blank, C., Rollinghoff, M., 1993. Langerhans cells transport Leishmania major from the infected skin to the draining lymph node for presentation to antigen-specific $\mathrm{T}$ cells. Eur. J. Immunol. 23, 1595-1601.

Muraille, E., De Trez, C., Pajak, B., Torrentera, F.A., De Baetselier, P., Leo, O., Carlier, Y., 2003. Amastigote load and cell surface phenotype of infected cells from lesions and lymph nodes of susceptible and resistant mice infected with Leishmania major. Infect. Immun. 71, 2704-2715.

Olivier, M., Baimbridge, K.G., Reiner, N.E., 1992. Stimulus-response coupling in monocytes infected with Leishmania. Attenuation of calcium transients is related to defective agonist-induced accumulation of inositol phosphates. J. Immunol. 148, 1188-1196. 
Pietschmann, P., Cush, J.J., Lipsky, P.E., Oppenheimer-Marks, N., 1992. Identification of subsets of human T cells capable of enhanced transendothelial migration. J. Immunol. 149, 1170-1178.

Poston, R.N., Johnson-Tidey, R.R., 1996. Localized adhesion of monocytes to human atherosclerotic plaques demonstrated in vitro: implications for atherogenesis. Am. J. Pathol. 149, 73-80.

Pryce, G., Santos, W., Male, D., 1994. An assay for the analysis of lymphocyte migration across cerebral endothelium in vitro. J. Immunol. Methods 167, 55-63.

Randolph, G.J., Inaba, K., Robbiani, D.F., Steinman, R.M., Muller, W.A., 1999. Differentiation of phagocytic monocytes into lymph node dendritic cells in vivo. Immunity 11, 753-761.

Santos, W.L., Andrade, Z.A., Rocha, H., 1994. Dynamics of connective matrix deposition in acute experimental E. coli pyelonephritis in rats. Exp. Toxicol. Pathol. 46, 63-69.

Schor, H., Vaday, G.G., Lider, O., 2000. Modulation of leukocyte behavior by an inflamed extracellular matrix. Dev. Immunol. 7 , $227-238$.

Springer, T.A., 1995. Traffic signals on endothelium for lymphocyte recirculation and leukocyte emigration. Annu. Rev. Physiol. 57, $827-872$.

Stamper Jr., H.B., Woodruff, J.J., 1976. Lymphocyte homing into lymph nodes: in vitro demonstration of the selective affinity of recirculating lymphocytes for high-endothelial venules. J. Exp. Med. 144, 828-833.

Stamper Jr., H.B., Woodruff, J.J., 1977. An in vitro model of lymphocyte homing. I. Characterization of the interaction between thoracic duct lymphocytes and specialized high-endothelial venules of lymph nodes. J. Immunol. 119, 772-780.
Steffen, B.J., Breier, G., Butcher, E.C., Schulz, M., Engelhardt, B., 1996. ICAM-1, VCAM-1, and MAdCAM-1 are expressed on choroid plexus epithelium but not endothelium and mediate binding of lymphocytes in vitro. Am. J. Pathol. 148, 18191838.

Symon, F.A., McNulty, C.A., Wardlaw, A.J., 1999. P- and L-selectin mediate binding of $\mathrm{T}$ cells to chronically inflamed human airway endothelium. Eur. J. Immunol. 29, 1324-1333.

Takagi, J., Springer, T.A., 2002. Integrin activation and structural rearrangement. Immunol. Rev. 186, 141-163.

Teixeira, M.C., de Jesus Santos, R., Sampaio, R.B., Pontes-deCarvalho, L., dos-Santos, W.L., 2002. A simple and reproducible method to obtain large numbers of axenic amastigotes of different Leishmania species. Parasitol. Res. 88, 963-968.

van Kooyk, Y., Weder, P., Heije, K., Figdor, C.G., 1994. Extracellular $\mathrm{Ca} 2+$ modulates leukocyte function-associated antigen-1 cell surface distribution on $\mathrm{T}$ lymphocytes and consequently affects cell adhesion. J. Cell Biol. 124, 1061-1070.

Vora, A.J., Perry, M.E., Hobbs, C., Dumonde, D.C., Brown, K.A., 1995. Selective binding of peripheral blood lymphocytes to the walls of cerebral vessels in frozen sections of human brain. J. Immunol. Methods 180, 165-180.

Warren, J.S., Jones, M.L., Flory, C.M., 1993. Analysis of monocyte chemoattractant protein 1-mediated lung injury using rat lung organ cultures. Am. J. Pathol. 143, 894-906.

Weiser, W.Y., Remold, H.G., David, J.R., 1985. Generation of human hybridomas producing migration inhibitory factor (MIF) and of murine hybridomas secreting monoclonal antibodies to human MIF. Cell Immunol. 90, 167-178. 